\title{
Screening of Extractable Nuclear Antibodies by ELISA in Patients with Connective Tissue Disorders in a Tertiary Care Hospital
}

\author{
S. Punitha Ranjitham", I.M. Rejitha, G. Sucilathangam and C. Revathy \\ Department of Microbiology, Tirunelveli Medical College, Tirunelveli - 627011 , \\ Tamil Nadu, India \\ *Corresponding author
}

\section{Key words \\ Autoimmune diseases, Extractable Nuclear Antibodies, ELISA, ANA \\ Article Info \\ Accepted: \\ 04 February 2018 \\ Available Online: \\ 10 March 2018}

\section{A B S T R A C T}

Autoimmune diseases occur in 3-5\% of the population as a result of myriad of genetic and environmental factors that lead to altered immune reactivity. The alterations in the immune system initiated by a loss of immunological tolerance to self-antigens lead to the development of autoreactive phenomena that can be detected in the peripheral blood. The present study was undertaken to detect the Extractable Nuclear Antibodies present in the study population. This study was conducted for a period of 1 year in 100 patients attending Rheumatology department. 50 patients had signs and symptoms related to connective tissue disorders and were ANA positive. Another 50 patients had no signs and symptoms related to CTD and were ANA negative. Out of 100 patients tested, $28(56 \%)$ of ANA positive patients and $3(6 \%)$ among control group were found to be positive for extractable nuclear antibodies by ENA screening ELISA. Among ENA positive subjects most common age group was $30-39$ years that is $38.7 \%$ were in this age group. Extractable Nuclear Antibodies were found most predominantly in females (28 out of 31) 90.3\% compared to males (3out of 31) 9.7\%. Autoimmune connective tissue diseases are rare group of diseases with significant impact on patient's quality of life and socioeconomic aspects. Antibodies against extractable nuclear antigens (ENAs) are useful diagnostic markers for various autoimmune connective tissue diseases.

\section{Introduction}

Autoimmune diseases occur in 3-5\% of the population (Kavanaugh et al., 2000) as a result of myriad of genetic and environmental factors that lead to altered immune reactivity (Jacobson et al., 1997; Marrack et al., 2001). The alterations in the immune system initiated by a loss of immunological tolerance to selfantigens lead to the development of auto reactive phenomena that can be detected in the peripheral blood. Alteration in immune system occurs due to various genetic and environmental factors leading to development of auto reactive phenomenon by a loss of immunological tolerance to self-antigens that can be detected in the peripheral blood in the form of the autoantibodies (Salaman, 2003). Autoimmune connective tissue diseases (AI CTDs) are a group of polygenic disorders often having heterogeneous and overlapping clinical features. Certain features are common 
to all of them viz. autoimmunity, vascular abnormality, arthritis/ arthralgia and cutaneous manifestations (Jacob and Sontheimer).

Connective tissue diseases (CTDs) are a collection of autoimmune disorders characterised by antinuclear antibodies (ANAs) in the serum of the patients. CTDs relevant to dermatology are Systemic Lupus Erythematosus, drug induced lupus, Scleroderma, Dermatomyositis, Sjogren's syndrome and mixed connective tissue diseases. ANAs are autoantibodies directed against various cell organelles including cytoplasm, nuclei, nucleoli, subcellular structures and cell surfaces (Lee). The antigens recognised are mainly proteins and nucleic acids. These autoantibodies are involved in the pathogenesis of the disease and also help in diagnosing and treating the disease as well as in assessing the prognosis of the disease.

ANA are a specific class of autoantibodies that have the capability of binding and destroying certain structures within the nucleus of the cells. These antibodies are involved in the disease pathogenesis, and they also constitute the basis for diagnosis and treatment of CTD (IADVL Textbook of Dermatology).

It is currently accepted that ANA contains two major types of antibodies. The first group includes antibodies against DNA and histones which are indicative of SLE and drug-induced lupus erythematosus (DILE), respectively. The second group includes autoantibodies to extractable nuclear antigens (ENA) which are obtained by extracting them from nuclei with saline. The autoantibodies to Smith antigen (Sm) ribonucleoproteins (RNP), Ro/SSA or La/SSB, Scl-70, histidyl-tRNA synthetase (Jo$1)$, and PM1 are in this group.

Although most of these ENA are disease specific, a significant overlap exists.
Sensitivity and specificity may also vary depending upon the type of underlying CTD (Kumar et al., 2009). Presence of autoantibodies in the sera of patients constitutes one of the criteria used for diagnosis of CTD and used to help diagnose and distinguish between autoimmune disorders as well as to monitor autoimmune disease progression. ENA screening tests can be done using enzyme-linked immunosorbent assay.

The techniques used for detection of specificANA includes Enzyme Linked Immuno Sorbent Assay (ELISA), Crithidia luciliae Immunofluorescence (CLIF), Farr assay (radio-labelled assay), Counter current immune electrophoresis (CIE), Passive haemagglutination assay (PHA), Western blot, Dot blot, Line blot Immunoassay, Multiplex Immunoassay (MIA), Flow cytometry, Antigen microarray.

ELISA method is simple to perform, quantitative, and offer high throughput volume. ELISA is becoming the most widely used method (Robbins et al., 1957). The European Consensus Workshops recommended that ENA testing be performed by two or more methods (Van Venrooij et al., 1991).

This recommendation is difficult to implement, particularly in the current era of cost containment. Rather, it may be possible to achieve the same outcome by combining the sensitivity of the ANA test with the specificity of a test for anti-ENA antibodies. We consider CIEP to be the most appropriate method for detecting anti-ENA antibodies because of its high specificity. In practice, most laboratories have chosen to use an ELISA-based method for its simplicity, convenience, and rapid turnaround time. This study was done to detect the presence of Extractable Nuclear Antibodies in ANA positive subjects and ANA negative controls. 


\section{Materials and Methods}

After getting approval from the Institutional Ethical Committee, a prospective study was conducted at the Department of Microbiology in Tirunelveli Medical College during the period of 2016-17. A total of 100 blood samples were collected. 50 clinically suspected CTD with complaints related to connective tissue disorders like skin rashes, photosensitivity, joint pain, respiratory symptoms and were ANA positive, and 50 controls without any clinical symptoms related to connective tissue disorders and with ANA negative in the age group of 15- 65 years of both sexes and tested for ENA screening by ELISA. Informed consent was obtained from all patients who participated in the study. Questionnaire regarding the clinical profile, was recorded.

\section{Sample collection}

After getting informed consent, blood was collected from median cubital vein, selected area was cleaned with surgical sprit and allowed to air dry, $5 \mathrm{ml}$ blood was collected. From the specimen vial, serum was separated and transferred to sterile screw capped leakproof tube.

ENA screening was done by ELISA. Diluted samples were incubated with ENA antigens (SSA, SSB, m/RNP, Scl- 70 and Jo-1) bound to the solid surface of a microtiter well.

If $\operatorname{IgG}$ antibodies against any of these antigens were present in the samples they will bind to the respective antigen forming antigenantibody complexes. Residual sample was eliminated by aspirating and washing. Conjugate (alkaline phosphatase labeled antihuman $\mathrm{IgG}$ ) was added and will bind to these complexes. Unbound conjugate was removed by aspiration and washing. Substrate was then added and incubated. In the presence of bound enzyme the substrate was converted to a coloured end product. The absorbance of this end product can be read spectrophotometrically at $405 \mathrm{~nm}$ (reference 600-630 nm).

\section{Results and Discussion}

A total of 100 patients were included in the study.50 ANA positive subjects with signs and symptoms related to connective tissue disorders (CTD) were evaluated against 50 ANA negative controls without any signs and symptoms related to CTD. This study was conducted for a study period of one year from April 2016 to March 2017. The study population mainly consisted of patients attending Rheumatology Department, Tirunelveli Medical College Hospital, Tirunelveli.

The present study showed that ANA positive subjects were $40 \%$ in the ages of 30-39 and negative subjects were $34 \%$ in the ages of 20 29 (Table 1).

In this study, $92 \%$ females were ANA positive compared to males $8 \%$.

The sensitivity of the ENA screening test was $56 \%$. The specificity of the test was $94 \%$. The positive predictive value of the test was $90.3 \%$. The negative predictive value of the test was $68.1 \%$,

This study was conducted on 100 subjects which included 50 ANA positive cases and 50 ANA negative controls. Among the cases, $40 \%$ were in the age group of $30-39$ and $34 \%$ were in the age group of 20-29 among the controls. The mean age of cases was $36.1 \pm$ 13.0 years and the mean age of controls was $36.8 \pm 11.0$ years.

In this study, 92\% females were ANA positive compared to males $8 \%$. 
Table.1 Age wise distribution of anti ENA positive subjects

\begin{tabular}{|l|c|c|}
\hline \multicolumn{1}{|c|}{ Age } & ENA Positive $\left(\mathrm{no}_{\mathbf{1}} \mathbf{3 1}\right)$ & Percentage \\
\hline$<20$ & 2 & $6.5 \%$ \\
\hline $\mathbf{2 0 - 2 9}$ & 5 & $16.1 \%$ \\
\hline $\mathbf{3 0 - 3 9}$ & 12 & $38.7 \%$ \\
\hline $\mathbf{4 0 - 4 9}$ & 7 & $22.6 \%$ \\
\hline $\mathbf{5 0 - 5 9}$ & 4 & $12.9 \%$ \\
\hline $60+$ & 1 & $3.2 \%$ \\
\hline
\end{tabular}

Table.2 Anti ENA positivity among ANA positive subjects and ANA negative controls

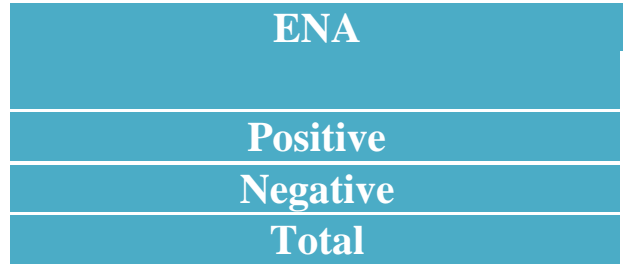

\begin{tabular}{|r|r|}
\hline Pos \\
\hline 28 \\
\hline 50 \\
\hline
\end{tabular}

In a study conducted by Budhrani et al., incidence of CTD in Males (20\%) and females $(80 \%)$ were seen making incidence ratio of $1: 4$ respectively. Autoimmune connective tissue disease is commonly seen in middle age with average age of occurrence ranging from 20-50 years. This result is in accordance with reports from various authors viz. Malaviya et al., [M: $\mathrm{F}=1: 8]$ and Lee et al., [M: $\mathrm{F}=1: 6]$ (Lee; Malaviya et al., 1988). The median age of onset in present study was around 40 years while study by Malaviya et al., had 24years and Masi et al., had 31 years (Masi and Kaslow, 1978) as a median age. The most common age group among ENA positive subjects was 30-39 years and females (28) $90.3 \%$ were most commonly affected compared to 3 males (9.7\%).

In the present study, 28 ANA positive subjects and 3 ANA negative subjects were positive for ENA (Table 2). Performance characteristics of the ENA screening test were analysed. Sensitivity of the test was $56 \%$, Specificity of the test was $94 \%$, Positive predictive value $90.3 \%$, and
Negative predictive value $68.1 \%$. Among the 50 controls 3 were ENA positive. (6\%). Although lower amounts of autoantibodies can be found in the serum of apparently normal individuals as well, particularly in older age groups, a spurt in titres is seen in patients of autoimmune diseases (Kumar et al., 2009). The frequency of autoantibodies in normal individuals ranges between 0.5 and 27\% (Gilburd et al., 2004).

The prevalence of anti-ENA positivity combined with a negative ANA was three out of $468(0.64 \%)$ as found by Manoussakis et al., (1988). The ENA ELISA used in this study is becoming the most widely used method not only for routine screening. Thus this study emphasises the role of Anti ENA antibody testing in the diagnosis of connective tissue disorders.Autoimmune connective tissue diseases are rare group of diseases with significant impact on patient's quality of life and socioeconomic aspects.

Antibodies against extractable nuclear antigens (ENAs) are useful diagnostic 
markers for various autoimmune connective tissue diseases. ELISA evaluated in this study has the advantage over the other techniques is that it enables the detection of antibodies with additional specificities. Its major advantages are its lower price and the fast and simultaneous detection of different autoantibodies in a single serum. In this study anti ENA antibodies were found in 31 ANA positive patients. In conclusion, ENA ELISA is a valid method for the simultaneous detection of various autoantibodies in autoimmune connective tissue disorder.

\section{Acknowledgement}

The authors are gratefully acknowledged The Dean, Tirunelveli Medical College Hospital, Tirunelveli, Tamil Nadu, The Staff of Rheumatology, and The Staff of Microbiology, Tirunelveli Medical College Hospital.

\section{References}

Gilburd B, Abu-Shakra M, Shoenfeld Y, Giordano A, Bocci BE, Monache FD et al., Autoantibodies profile in the Sera of Patients with Sjogren's Syndrome: The ANA Evaluation - A Homogenous, Multiplexed System. Clin Dev Immunol 2004; 11:53-6.

IADVL Textbook of Dermatology, edition 4th chapter 42, Pp. 1705.

Jacob H, and Sontheimer R. Autoantibodies encountered in patients with autoimmune connective tissue disease In: Dermatology by Bolognia, 2nd edition; pg 549 -50.

Jacobson DL, Gange SJ, Rose NR, Graham $\mathrm{NMH}$. Epidemiology and estimated population burden of selected autoimmune diseases in the United States. Clinical Immunology and
Immunopathology. 1997; 84(3):223243, 1997.

Kavanaugh A, Tomar R, Reveilk J, Solomon $\mathrm{DH}$, Homburger HA. Guidelines for clinical use of the antinuclear antibody test and tests for specific autoantibodies to nuclear antigens. Arch Pathol Lab Med 2000; 124: 71 81.

Kumar Y, Bhatia A, Minz RW. Antinuclear antibodies and their detection methods in diagnosis of connective tissue diseases: a journey revisited. Diagn Pathol 2009; 4:1.

Kumar Y, Bhatia A, Minz RW. Antinuclear Antibodies and their Detection Methods in Diagnosis of Connective Tissue Diseases: a Journey Revisited. Diagn Pathol 2009; 4:1.

Lee L. Lupus erythematosus. In: Dermatology by Bolognia, 2nd edition; pg 561.

Lee L. Lupus erythematosus. In: Dermatology by Bolognia, 2nd edition; pg 561.

Malaviya AN, Singh RR, Kumar De A, Kumar A, Aradhyne S., SLE in North India 1988; 36:476-80.

Manoussakis MN, Garalea KL, Tzioufas AG, et al., testing for antibodies to ENA and tods DNA is not indicated in FANA-negative sera. Clin Rheumatol. 1988; 7:465-9.

Marrack P, Kappler J, Kotzin BL. Autoimmune disease: why and where it occurs. Nature Medicine. 2001; 7(8):899-905.

Masi AT, and Kaslow RA. Sex effects in SLE: A clue to pathogenesis. Arthritis. Rheumatology 1978; 21:480.

Robbins WC, Homan HR, Deicher H, Kunkel HG: Complement fixation with cell nuclei and CNA in lupus erythematosus. Proceedings of the 
Society for Experimental Biology (New York) 1957, 96:575.

Salaman MR. A two-step hypothesis for the appearance of autoimmune disease. Autoimmunity 2003; 36(2):57-61.
Van Venrooij WJ, Charles P, Maini RN. The consensus workshops for the detection of autoantibodies to intracellular antigens in rheumatic diseases. J. Immunol. Methods. 1991; 140:181-189.

\section{How to cite this article:}

Punitha Ranjitham, S., I.M. Rejitha, G. Sucilathangam and Revathy, C. 2018. Screening of Extractable Nuclear Antibodies by ELISA in Patients with Connective Tissue Disorders in a Tertiary Care Hospital. Int.J.Curr.Microbiol.App.Sci. 7(03): 112-117.

doi: https://doi.org/10.20546/ijcmas.2018.703.012 